\title{
REDES DE DESEJOS CONSONANTES: A IMPOSSIBILIDADE DA POLIFASIA COGNITIVA NA ERA DA PÓS-VERDADE
}

\author{
Networks of consonant desires: the impossibility of cognitive \\ polyphasia in the post-truth age
}

\author{
Redes de deseos consonantes: la imposibilidad de la polifasia cognitiva \\ en la era de la posverdad
}

\begin{abstract}
Arthur Walber Viana
Mestrando no Programa de Pós-Graduação em Comunicação e Informação (PPGCOM) da Universidade Federal do Rio Grande do Sul

(UFRGS). Bolsista CAPES. arthurwalber@hotmail.com
\end{abstract}

Valdir Jose Morigi Doutor em Sociologia pela Universidade de São Paulo (USP) e professor titular da Faculdade de Biblioteconomia e Comunicação (FABICO) e do Programa de Pós-graduação em Comunicação e Informação (PPGCOM) da Universidade Federal do Rio Grande do Sul (UFRGS). valdir.morigi@ufrgs.br

\begin{abstract}
Resumo
Reflete sobre como se constroem as versões de verdade diante do fenômeno da pós-verdade. Para tanto, propõe um aprofundamento teórico sobre as maneiras que indivíduos formulam seus pontos de vista e sobre como os seus modos de saber se relacionam, em âmbito individual e social. A partir de perspectivas da Psicologia Social e da Sociologia, situa o fenômeno da pós-verdade historicamente. Vê nas novas formas de socialização da informação e na lógica das redes sociais digitais movimentos que ampliam a busca por consonância cognitiva e, assim, afastam-nos da diversidade de pensamentos. Tal ocorrência dificulta a efetivação da hipótese da polifasia cognitiva (a construção dialética de saberes mais tolerantes a partir da coexistência de diferentes tipos de racionalidade em um mesmo indivíduo ou grupo social), abrindo espaço para discursos de ódio e fascismos.
\end{abstract}

Palavras-chave: Pós-verdade. Polifasia cognitiva. Teoria da Dissonância Cognitiva.

\section{Abstract}

The article reflects on how the versions of truth are constructed in the face of the post-truth phenomenon. In order to do so, it proposes a theoretical understanding of the ways in which individuals formulate their points of view and how their knowledge relates, both individually and socially. From the perspectives of Social Psychology and Sociology, situates the posttruth phenomenon historically. It sees in the new forms of socialization of information and in the logic of digital social networks movements that broaden the search for cognitive consonance and thus distance us from the diversity of thoughts. Such occurrence hinders the realization of the hypothesis of cognitive polyphasia (the dialectical construction of more 
tolerant knowledge from the coexistence of different types of rationality in the same individual or social group), opening space for discourses of hatred and fascism.

Key words: Post-truth. Cognitive polyphasia. Theory of Cognitive Dissonance.

\section{Resumen}

Refleja sobre cómo se construyen las versiones de verdad ante el fenómeno de la posverdad. Para ello, propone una profundización teórica sobre las maneras que los individuos formulan sus puntos de vista y sobre cómo sus modos de saber se relacionan, en ámbito individual y social. A partir de perspectivas de la Psicología Social y de la Sociología, sitúa el fenómeno de la pos-verdad históricamente. Ve en las nuevas formas de socialización de la información y en la lógica de las redes sociales digitales movimientos que amplían la búsqueda de consonancia cognitiva y, así, nos alejan de la diversidad de pensamientos. Esta ocurrencia dificulta la efectividad de la hipótesis de la polifasia cognitiva (la construcción dialéctica de saberes más tolerantes a partir de la coexistencia de diferentes tipos de racionalidad en un mismo individuo o grupo social), abriendo espacio para discursos de odio y fascismos.

Palabras clave: Posverdad. Polifasia cognitiva. Teoría de la disonancia cognitiva.

\section{INTRODUÇÃO}

Em 2016, o dicionário britânico Oxford elegeu "pós-verdade" como a palavra do ano ${ }^{1}$, fato que jogou holofotes sobre o termo, elevando-o a debates científicos sobre sua validade e conceituação. O dicionário, em sua definição, apresenta a pós-verdade como um adjetivo ${ }^{2}$ "[...] relativo a ou denotando circunstâncias em que fatos objetivos são menos influentes na formação da opinião pública do que apelos à emoção e crença pessoal" (THE WORD OF THE YEAR..., 2017, tradução nossa). De início, portanto, constata-se que o fenômeno da pósverdade não remete à mentira; ele se refere, somente, a um ponto onde a verdade dos fatos perde em relevância frente a crenças pessoais já estabelecidas, ressaltando-se o peso das emoções e dos afetos na internalização das informações que recebemos e apreendemos de outros sujeitos e dos objetos que nos cercam. Ao que cabe a pergunta: há novidade no fenômeno da pós-verdade? Houve, na história, momento no qual mulheres e homens não privilegiaram crenças individuais consolidadas ante qualquer informação nova que se opusesse a elas, independente de quão apegados ao real fossem os dados discordantes?

Diversos estudos psicológicos revelam a dificuldade que temos em contestar e renunciar às nossas certezas, como a Teoria da Dissonância Cognitiva (TDC) de Festinger

1 Disponível em: https://en.oxforddictionaries.com/word-of-the-year/word-of-the-year-2016 (em inglês). Acessado em: 09/05/2017.

2 O dicionário Priberam, de língua portuguesa, classifica pós-verdade também como substantivo. Disponível em: https://priberam.pt/dlpo/p\%C3\%B3s-verdade. Acessado em: 22/05/2017. 
(1975), publicada inicialmente em 1956. O estudo explicita a tendência que temos em evitar ou em deslegitimar informações que conflitem com crenças pessoais preexistentes, em um ato de defesa contra os desconfortos causados por contradições oriundas das complexas relações sociais cotidianas. Em contraponto, o conceito de polifasia cognitiva (MOSCOVICI, 1978; JOVCHELOVITCH, 2004) aponta para a possibilidade da coexistência de modalidades distintas de conhecimento, quando diferentes tipos de racionalidade e saberes coabitam um mesmo indivíduo ou grupo social, excedendo dicotomias cartesianas que pregam que algo seja ou isso ou aquilo.

Ambos os fenômenos são possíveis no cenário de pós-verdade que desponta, catalisado pelas novas formas de socialização da informação a partir das redes sociais digitais: no primeiro, evita-se ou se refuta a importância da informação que diverge, garantindo a sobrevivência consonante das crenças previamente interiorizadas; no outro, compreende-se cada saber em seu contexto, legitimando sua existência e o incorporando, dialeticamente, às noções de mundo e às crenças estabelecidas, possibilitando o surgimento de novas categorias de saber e de representações a partir da diversidade de conhecimentos absorvidos.

Antes que haja uma superação e nos habilitemos a acrescentar o prefixo pós a qualquer fenômeno, exige-se que este tenha estado em pleno vigor, até chocar-se com suas limitações. A modernidade, fundada na razão secular da ciência, impôs a supremacia de uma "Verdade objetiva", una, mensurável e verificável; ela estaria, assim, ao nosso alcance. As promessas do período, contudo, não foram cumpridas, e o alarme da crise do projeto moderno soa alto há décadas. O momento de transição paradigmática (SANTOS, 1997) se prolonga, ainda insolúvel e inquietante, nos cobrando posicionamentos e indicando que talvez a sensação de transitoriedade seja permanente. Este é o cenário em que a pós-verdade desvela o desapego a fatos concretos quando construímos nossas verdades, leituras plurais sobre os fatos do mundo reforçadas constantemente ao ecoarem em redes sociais de consonância.

As interrogações que se elevam, portanto, questionam nossa capacidade de sobrevivência coletiva em um universo de verdades múltiplas, ao passo que a Verdade moderna se comprova apenas mais uma. Nos enclausuraremos junto a semelhantes, nossos espelhos, deslegitimando qualquer discurso divergente? O respeito à pluralidade de versões abarcará discursos de ódio e de fascismos? Ou seremos capazes de, a partir da diferença, formatar saberes mais tolerantes? Que pós-verdade estamos construindo e, mais importante, qual queremos - uma vez que o fenômeno está posto - construir? 


\section{PÓS-VERDADE, UMA BREVE HISTÓRIA}

Ainda que não se saiba exatamente quando o termo "pós-verdade" foi forjado, foi na década de 1990 que ele ultrapassou a mera definição temporal de momento após a verdade vir à tona; a partir dali conotou-se um novo sentido, o de irrelevância da verdade ou, como preferimos, momento em que fatos concretos já não importam tanto, uma vez que relativos. Com essa significação, o termo consta primeiro em artigo do dramaturgo Steve Tesich, em 1992, na revista norte-americana The Nation (THE WORD OF THE YEAR..., 2017, tradução nossa); em 2004, surge o livro “A Era da Pós-Verdade”, de Ralph Keyes, que caracteriza a nova era como um tempo de tolerância à desonestidade.

A popularização de "pós-verdade", contudo, se daria mesmo em 2016, em especial devido à eleição norte-americana daquele ano, vencida por Donald Trump, do Partido Republicano; e à votação do "Brexit", também em 2016, plebiscito que decidiu pela saída do Reino Unido da União Europeia. Nestas duas ocasiões, destacou o dicionário Oxford ao reverenciar "pós-verdade" com o título de palavra do ano, abundou o desapego à verdade factual, com fortes apelos, por parte das partes interessadas, ao emocional das e dos votantes. A popularização do termo foi tal que, em um ano, a utilização de "pós-verdade" pela imprensa mundial cresceu em $2.000 \%$ (dois mil por cento) (THE WORD OF THE YEAR..., 2017, tradução nossa).

\section{A (IR)RACIONALIDADE MODERNA: A VERDADE A SUPERAR?}

Apesar da aparência de novidade, ao ressurgir no debate público mundial massivamente, o fato é que o fenômeno que agora chamamos "pós-verdade" tem acompanhado o desenvolvimento do conhecimento humano desde seu princípio. Uma frase atribuída ao filósofo e matemático britânico Bertrand Russell parece definir pós-verdade com surpreendente exatidão, se considerarmos que precedeu o nascimento do termo em algumas décadas: "Aquilo que os homens de fato querem não é o conhecimento, mas a certeza". Distinção semelhante faz Hannah Arendt (1967), ao separar a verdade filosófica da verdade dos fatos; esta segunda, afirma, pertence ao mesmo domínio da opinião e é, necessariamente, política, uma vez que relativa: “A verdade de facto [...] é sempre relativa a várias pessoas: 
[...] é estabelecida por testemunhas e repousa em testemunhos; existe apenas na medida em que se fala dela, mesmo que se passe em privado. É política por natureza" (ARENDT, 1967, n.p.).

Russell viveu a transição do século XIX para o século XX; Arendt nasceu em 1906. Ambos assistiram a duas guerras mundiais, o que torna compreensível suas inquietudes em relação ao projeto moderno. De forma sucinta, Russell destaca a busca da modernidade pela certeza do concreto, único saber legitimado pelo racionalismo secularizado característico do período que, ao superar os mitos e as lendas religiosas, impôs a lógica da objetividade científica ao saber, em visível deslumbramento frente a possibilidade de enfim alcançar a Verdade Pura. Arendt (1967), por sua vez, sublinha o relativismo dessas certezas.

Embriagada por sua busca pela verdade, a ciência moderna se fundamentou na racionalização extrema da vida social e individual, convertendo-se, ela própria, “[...] num problema sem solução, gerador de recorrentes irracionalidades” (SANTOS, 1997, p.34). Em um rápido exercício, Santos (1997) compila algumas:

\begin{abstract}
A acumulação das irracionalidades no perigo iminente de catástrofe ecológica, na miséria e na fome a que é sujeita uma grande parte da população mundial - quando há recursos disponíveis para lhe proporcionar uma vida decente e uma pequena minoria da população vive numa sociedade de desperdício e morre de abundância -, na destruição pela guerra de populações e comunidades em nome de princípios étnicos e religiosos que a modernidade parecia ter descartado para sempre, na droga e na medicalização da vida como solução para um quotidiano alienado, asfixiante e sem solução - todas estas e muitas outras irracionalidades se acumulam ao mesmo tempo que se aprofunda a crise das soluções que a modernidade propôs, entre elas o socialismo e o seu máximo de consciência teórica possível, o marxismo. As irracionalidades parecem racionalizadas pela mera repetição (SANTOS, 1997, p.43).
\end{abstract}

As contradições da era moderna, cuja racionalização técnica-científica-industrial, ao mesmo tempo que vigorosa, produziu estas e tantas outras irracionalidades, colocam em xeque a crença no progresso humano - ao menos nesse modelo de progresso, que levou Giddens (1991) a chamar o século XX de século da guerra: “Até agora, mais de 100 milhões de pessoas foram mortas em guerras, uma proporção mais alta da população do mundo do que no século XIX, mesmo considerando-se o crescimento geral da população” (GIDDENS, 1991, p.19).

As promessas de emancipação, reduzidas às possibilidades do capitalismo, já não podem ser entregues (SANTOS, 1997). Como seguir a acumulação de capital por meio do consumo dos bens naturais e da força humana em um mundo expandido e explorado a seu 
máximo? A lógica do capitalismo é devastadora, pois “[...] o capital tende a apropriar-se de modo autodestrutivo, tanto da força do trabalho, como do espaço, da natureza e do meio ambiente em geral"' (SANTOS, 1997, p.44).

Em descrédito, a verdade moderna, una e científica, é suspensa, e todas as suas instituições, das democracias representativas dos Estados-nação ao jornalismo, passam por crises e suspeições. E se a verdade que nos era dada como única se mostra falha, agora, junto a ela, elencam-se várias: "A perspectiva pós-moderna vê uma pluralidade de reivindicações heterogêneas de conhecimento, na qual a ciência não tem um lugar privilegiado" (GIDDENS, 1991, p.12). A própria razão, santificada pelo pensamento moderno como a responsável por elevar a mente humana a patamares superiores de sabedoria, o caminho da luz da lógica científica e exata, vê-se sob inquérito.

\subsection{A razão da razão é cooperar}

Mercier e Sperber $(2011$; 2017) contestam os fundamentos da definição de razão, comumente tida como um superpoder cognitivo que ajuda indivíduos a alcançar um conhecimento mais profundo para, dessa maneira, os habilitar a tomar decisões melhores em suas vidas. Fosse essa de fato a função da razão, questionam os autores, seria difícil explicar porque ela falha com tamanha frequência em trazer as pessoas a uma concordância ao redor de um tema, muitas vezes inclusive ressaltando suas discordâncias - mesmo pesquisadoras e pesquisadores, porta-vozes legitimados da razão, não alcançam consensos. Isso impõe, logo, que ou algumas pessoas são racionais enquanto outras não o são, uma vez que raciocinam de maneiras distintas; ou, como defendem os autores, que a nossa ideia de quais são as atribuições da razão é que estão equivocadas: ela deve ser abordada como um traço evolutivo, uma adaptação desenvolvida pelos humanos a partir de seus nichos hiper-sociais (MERCIER, SPERBER, 2011; 2017). Incomodar-se por ela não nos iluminar com sabedoria, levando-nos todos ao que é verdadeiro, faria tanto sentido quanto reclamar que os olhos não estão escutando bem.

Segundo essa perspectiva interacionista, portanto, é inútil avaliar a razão como uma faculdade individual, uma vez que sua evolução ocorre num encontro complexo de subjetividades, afirmando-se como produto de nossa socialização: "Razão, nós sustentamos, é antes e acima de tudo uma competência social" (MERCIER, SPERBER, 2017, n.p., tradução nossa). As finalidades da razão, descartada como superpoder cognitivo capaz de nos elevar à Verdade Suprema, seriam duas: 1) produzir razões para se justificar; e 2) produzir argumentos 
para convencer os outros (MERCIER, SPERBER, 2011; 2017). Dessa forma, a razão é acionada com o intuito de convencer o grupo com o qual convivemos que determinada ação, a qual julgamos pertinente por algum motivo, é útil a todos, ou ao menos à maioria; ou para avaliar se uma ação proposta por outro membro do grupo pode se tornar interessante a nós. Em suma, ajuda-nos a convencer os outros ou decidir do que seremos convencidos, ressaltando a importância da persuasão alheia em busca de sintonia e da ação conjunta do grupo para o desenvolvimento das sociedades.

\section{DISSONÂNCIA, CONSONÂNCIA E POLIFASIA COGNITIVAS: AS DIFERENÇAS QUE NOS CERCAM E NOS HABITAM}

A teoria argumentativa da razão de Mercier e Sperber $(2011$; 2017) dá maior nitidez ao debate sobre como o indivíduo forma suas opiniões e embasa suas decisões, essencial ao discutirmos o fenômeno da pós-verdade. Independente do quanto julgue agir conforme a razão, o fará sempre de maneira parcial: “A razão humana é tendenciosa [...] por encontrar massivamente justificações e argumentos que apoiam o ponto de vista do raciocínio" (MERCIER, SPERBER, 2017, n.p., tradução nossa). Tal movimento indica a busca do indivíduo por coerência, a fim de justificar a validade de uma crença preestabelecida perante seu grupo.

Troquemos coerência por consonância na frase anterior e nos aproximamos de um dos principais estudos na área da Psicologia que aprofunda o conceito do viés da confirmação ${ }^{3}$, revelando a dificuldade que temos em renunciar a certezas ou em aceitar pontos de vista contrários ao que sustentamos: a TDC - Teoria da Dissonância Cognitiva (FESTINGER, 1975) - debruçou-se sobre a seletividade dos nossos processos cognitivos, a fim de entender os mecanismos acionados no encontro de saberes distintos.

Festinger (1975) destaca a constante busca que empreendemos por um estado de consonância interno. Logo, toda vez que confrontados com informações que contradigam crenças preestabelecidas, somos postos em uma situação de desconforto cognitivo, que nos impulsionará a reestabelecer a coerência da nossa linha de pensamento. Para enfrentar a

3 Viés da confirmação (confirmation bias) é um conceito que vem sendo utilizado no campo da Psicologia de maneira bastante ampla e refere-se à tendência dos indivíduos em selecionar informações e memórias que corroborem a validade das visões de mundo já internalizadas. "Depois que adquirimos esquemas, estamos predispostos a fortalecê-los. Os pesquisadores em psicologia chamam esse processo de viés da confirmação - a tendência a acreditar no que reforça nossas noções preexistentes, fazendo-nos enxergar o que queremos enxergar" (PARISER, 2012, n.p.). 
dissonância cognitiva e nossas contradições internas, destaca-se três métodos (FESTINGER, 1975):

1) a busca ativa por informações que embasem a crença contestada;

2) a evitação de informações que possam aumentar a dissonância momentânea;

3) a redução da importância do fator dissonante.

Citando um hipotético caso de um fumante confrontado com notícias sobre os malefícios que o cigarro causa à saúde, Festinger (1975) cria um possível "trajeto cognitivo": ganha-se a ciência que fumar é prejudicial à saúde; contudo, andar de carro é também perigoso, talvez até mais, uma vez que, estatisticamente, mais pessoas morrem em acidentes de carro do que em decorrência do hábito de fumar; ainda assim, é socialmente aceito que se ande de carro; dessa forma, a dissonância que a informação "fumar faz mal" causa é reduzida, uma vez que se aceita a existência de outros males além do cigarro, até mesmo mais graves, como andar de carro. Festinger (1975) ressalta que esse é um trajeto: outros, como julgar o prazer do ato de fumar superior aos riscos à saúde, são também possíveis. Comum a todos casos, porém, será o desconforto causado pela dissonância e o esforço em reduzi-la.

De forma sucinta, portanto, o encontro com divergências nos levará a buscar, ativamente, dados que sustentem o nosso ponto de vista; a fugir de qualquer informação que contradiga a crença prévia, e o vigor da fuga será proporcional ao tamanho da dissonância (FESTINGER, 1975); e, em último caso, não sendo possível escapar à exposição a pontos de vista diversos, o esforço será em deslegitimá-los, reduzindo as suas dimensões de importância, como no hipotético caso do fumante descrito acima.

\subsection{A hipótese da polifasia cognitiva}

Em um contexto de infinitude no acesso (consciente ou não) a informações, potencializado pelo avanço das TICs (Tecnologias de Informação e Comunicação), a existência de fatores de dissonância é inevitável. Festinger já admitia tal realidade, afirmando que "[...] alguma dissonância é o estado usual de coisas" (FESTINGER, 1975, p.24). Aceitando-se a inevitabilidade da internalização de incoerências e do contraditório, a busca por consonância não pode se limitar a fuga e a deslegitimação dos discursos de oposição. Incorporar o diferente, percebendo-o em seu contexto, poderá trazer possibilidades mais interessantes no processo de reestabelecimento da consonância interna. Dialeticamente, o encontro de diferenças pode produzir novos saberes e categorizações, e aqui chegamos à hipótese da polifasia cognitiva, lançada por Moscovici (1978) e aprofundada por 
Jovchelovitch (2004): “As formas de saber coexistem e podem ser contraditórias, mas isso não é um problema se nós abandonamos a lógica formal e sua dualidade ao concebê-las como opostas e abraçamos uma perspectiva dialética” (JOVCHELOVITCH, 2004, p.27).

A polifasia cognitiva refere-se à coexistência dinâmica de modalidades distintas de conhecimento em um mesmo sujeito ou grupo social (MOSCOVICI, 1978; JOVCHELOVITCH, 2004). Jamais em consonância, esses diferentes tipos de racionalidade deslocam-se permanentemente, em constante evolução. A polifasia cognitiva, portanto, coloca-se como um passo além dos movimentos delimitados por Festinger (1975) na elaboração da TDC, de evitação e deslegitimação. Contudo, não a desvalida (e sequer tem tal pretensão): "É preciso [...] indagarmo-nos sobre as possibilidades comunicativas entre formas diferentes de saber, [...] se são possíveis, ou se o encontro entre saberes no mundo contemporâneo está destinado à exclusão e opressão" (JOVCHELOVITCH, 2004, p.28).

Ao mesmo tempo em que o conceito de polifasia se revela interessante para a compreensão dos modos de construção das percepções de mundo, deve ainda ser pensado na categoria da hipótese: "Esta hipótese incita-nos a ampliar nossas perspectivas. Os sistemas cognitivos devem ser concebidos como sistemas em desenvolvimento, e não apenas sistemas que tendem para o equilíbrio" (MOSCOVICI, 1978, p.287). A coexistência da diferença e o movimento dialético rumo a novas e mais tolerantes categorias de saber ainda competem com os mecanismos de defesa que buscam constantemente a consonância cognitiva, evitando e deslegitimando os modos de saber desviantes; permitir a discordância, acatando-a, por ora segue como mera suposição daquilo que seria possível.

\section{REDES DE DESEJOS CONSONANTES: OS CAMINHOS DA PÓS-VERDADE}

Como vimos, o fenômeno da pós-verdade não é novo: temos dificuldade em abrir mão de certezas e as informações que contestam crenças preexistentes causam-nos desconforto. Assim, no lugar de aceitar as diferentes compreensões de mundo e incorporá-las a conhecimentos prévios, possibilitando o surgimento de novos saberes a partir de um processo dialético, deslegitima-se os discursos que abordam perspectivas outras, que têm seus fundamentos contestados. A Teoria da Dissonância Cognitiva (FESTINGER, 1975) se sobrepõe à hipótese da polifasia cognitiva (MOSCOVICI, 1978; JOVCHELOVITCH, 2004).

Se o fenômeno da pós-verdade não é novo, no entanto, as formas com que as suas objetificações circulam nos meios sociais, definitivamente, são: as redes sociais, através das tecnologias de comunicação instantânea, transmitem, compartilham, recortam e editam 
infindáveis quantidades de informação, propagando, circulando e armazenando mais dados que em toda a história da humanidade. A título de ilustração, uma pesquisa de 2011 realizada pela IBM estimava que $90 \%$ dos dados online no mundo haviam sido criados naqueles dois últimos $\operatorname{anos}^{4}$, o que nos permite inferir que a avalanche de conteúdos tomará proporções cada vez maiores, disponibilizando uma imensidão de dados e de diferentes interpretações dos fatos, possibilitando, idealmente, contato com as mais variadas compreensões sobre os fenômenos históricos, sociopolíticos e culturais da humanidade.

Contudo, se por um lado as TICs potencializam a diversidade de discursos, por outro tornam raras as zonas de contato entre essas diferenças. $\mathrm{Na}$ internet, é cada vez menos provável que nos deparemos com pontos de vista que se oponham aos nossos; o contato se dá com nossos próprios espelhos e os únicos discursos (aparentemente) disponíveis servem ao reforço de crenças prévias: "[...] a bolha dos filtros nos cerca de ideias com as quais já estamos familiarizados (e com as quais já concordamos), dando-nos confiança excessiva em nossa estrutura mental" (PARISER, 2012, n.p.).

Um estudo realizado pelo próprio Facebook, em parceria com a Escola de Informação da Universidade de Michigan (EUA), baseado nos perfis de 10 milhões de usuários norteamericanos, mostrou que, dos links clicados por quem se considerava progressista, apenas $22 \%$ eram em fontes de informação que contrariavam suas visões de mundo; entre os conservadores, $29 \%$ dos cliques eram em notícias opostas às suas crenças ${ }^{5}$. Aos modos de pensar diferentes fica reservado, se tanto, a ironia e o escárnio: outro levantamento, este sobre intolerância nas redes, detectou que quase todos os comentários a respeito de etnia e de política são marcados pela negatividade $(97,6 \% \text { e } 97,4 \% \text {, respectivamente })^{6}$.

\subsection{A crise de credibilidade}

Seria rasteiro, contudo, reduzir tudo ao desenvolvimento tecnológico. Como discutimos anteriormente, as instituições da modernidade e suas autoproclamadas verdades estão sob sindicância, e não é diferente com o jornalismo, o "quarto poder" que, em termos

4 Disponível em: http://www-03.ibm.com/press/us/en/pressrelease/35633.wss. Acessado em: 06/06/2017.

5 O estudo foi realizado apenas com usuários que definiam em seus perfis sua inclinação política. Disponível em: http://science.sciencemag.org/content/early/2015/05/06/science.aaa1160.full. Acessado em: 30/05/2017.

6 Entre abril e junho de 2016, o Comunica Que Muda monitorou dez tipos de intolerância nas redes sociais (em relação à aparência das pessoas, às suas classes sociais, às inúmeras deficiências, à homofobia, misoginia, política, idade/geração, racismo, religião e xenofobia), analisando um total de 542.781 menções. Nos dez temas pesquisados, o percentual de abordagens negativas é superior a $84 \%$. Disponível em: http://18628-presscdn-0-21.pagely.netdna-cdn.com/wp-

content/themes/comunica/dist/dossie/dossie_intolerancia.pdf. Acessado em: 23/05/2017. 
ideais, traria a seus consumidores a Verdade objetiva e imparcial, em defesa do interesse público perante os três poderes estabelecidos nas repúblicas democráticas modernas Executivo, Legislativo e Judiciário. Tal Verdade, contudo, não nos é acessível (sequer é possível), e a submissão do jornalismo às corporações da indústria cultural e a consequente monologização de discursos na mídia nos apresentou uma realidade bastante distinta da prometida pelos idealistas.

O jornalismo tradicional revela-se, assim, como um partido da globalização neoliberal (RAMONET, 2012) e sua credibilidade como defensor de interesses públicos se desmancha no ar: "Os cidadãos desconfiam de uma imprensa que pertence a um punhado de oligarcas, que já controlam amplamente o poder econômico e que, frequentemente, são coniventes com os poderes políticos" (RAMONET, 2012, p.45). Segundo o ICJBrasil (Índice de Confiança na Justiça Brasileira), apenas 33\% dos brasileiros confiam nas emissoras de televisão, enquanto $37 \%$ confiam na mídia impressa ${ }^{7}$. Outra pesquisa, realizada nos Estados Unidos, também aponta para o cenário de erupção da credibilidade da mídia: apenas $17 \%$ dos norte-americanos julgam a imprensa como "bastante precisa"; $34 \%$ entendem que ela protege a democracia; e só $22 \%$ consideram que há preocupação com as pessoas utilizadas nas reportagens ${ }^{8}$.

\subsection{A pulverização da informação}

A internet apresenta uma possibilidade de existência ativa a quem até então tinha o direito apenas ao consumo passivo ${ }^{9}$. Novos canais de informação surgem, dispersos, e os webatores (RAMONET, 2012) consomem tanto quanto produzem, editam, publicam, comentam e

7 Índice elaborado pela Fundação Getúlio Vargas. Indica também que a crise de representação é generalizada: os partidos políticos contam com a confiança de apenas 7\% dos brasileiros; o Poder Judiciário, com 29\%; a instituição com maior respaldo é o Exército, que recebeu voto de confiança de $59 \%$ dos entrevistados. As redes sociais tiveram um índice de confiabilidade de $23 \%$. Números referentes ao primeiro semestre de 2016, publicação mais recente até a data deste artigo. Disponível em: http://bibliotecadigital.fgv.br/dspace/bitstream/handle/10438/17204/Relatorio-

ICJBrasil_1_sem_2016.pdf?sequence=1\&isAllowed=y. Acessado em: 22/05/2017.

8 Pesquisa realizada em parceria da Universidade de Chicago com a agência Associated Press e o American Press Institute. $\mathrm{O}$ estudo ainda traz um dado curioso, especialmente se analisado à luz da pós-verdade: desconfia-se da mídia, porém somente da mídia dos outros: a minha fonte de informação é confiável. Por exemplo, se apenas $17 \%$ dos entrevistados acreditam na precisão da imprensa, o número sobe para 34\% quando a pergunta é sobre a mídia que o próprio respondente consome. Enquanto $24 \%$ dizem que a mídia em geral não é "moral", $53 \%$ dos entrevistados consideram "moral" a mídia que eles próprios utilizam. Disponível http://www.mediainsight.org/PDFs/Meaning\%20of\%20Media/APNORC_Trust_The_Media_2017.pdf. Acessado em: 30/05/2017.

9 Não negamos aqui o papel da recepção, que influencia de maneira decisiva a apreensão do indivíduo a respeito das informações que recebe. Contudo, sublinhamos apenas que, com o desenvolvimento tecnológico, suas possibilidades de criação ativa foram vastamente ampliadas. 
compartilham conteúdos, tornando a circulação de informação rápida e difusa, contestando a verdade do jornalista. "Ele [internauta que domina os recursos da Web 2.0] disputa com ele [jornalista profissional] seu status privilegiado" (RAMONET, 2012, p.22). A rede é, por essência, a materialização das possibilidades da pós-verdade: há espaço (ainda que desiguais, frise-se) para todos os discursos; todos os modos de conhecimento poderão encontrar fundamentação, a partir de fontes variadas, as quais não sentirão necessariamente apego a princípios éticos básicos do jornalismo, como um estreito contato com a verdade factual - não por acaso, o fact checking (checagem de fatos, processo primário da produção jornalística) é um dos ramos mais promissores de um jornalismo pós-industrial ${ }^{10}$. As TICs, em especial as redes sociais digitais, são as catalisadoras da pós-verdade.

\subsection{A bolha algorítmica}

Quanto mais cliques em postagens de determinado perfil ou página, mais aquele conteúdo aparecerá com destaque: a bolha algorítmica ${ }^{11}$ nos revela apenas um recorte das possibilidades de mundo, partindo daquilo que supõe ser de nossa preferência. Diferente de outros momentos históricos, porém - no jornalismo moderno, por exemplo, sempre houve edição, recorte, parcialidade -, nos é mostrado aquilo que uma equação matemática julga que será de nosso agrado, a partir de fontes descentralizadas, com a finalidade de manter consumidores satisfeitos conectados e ativos em suas plataformas ${ }^{12}$. Uma mudança recente no algoritmo do Facebook exemplifica a política da empresa: postagens de familiares e amigos agora têm destaque maior que de empresas, mesmo as de notícia, ampliando a hermeticidade

10 Proliferam iniciativas voltadas à checagem de fatos no jornalismo. Algumas: Aos Fatos (https://aosfatos.org/); Lupa (http://piaui.folha.uol.com.br/lupa/); Truco (http://apublica.org/truco/). Artigo de Tai Nalon no estudo "O Jornalismo no Brasil em 2017”, realizado pela Abraji (Associação Brasileira de Jornalismo Investigativo) e pelo Farol Jornalismo, faz uma interessante abordagem do assunto, o relacionando à pós-verdade. Diponível em: https://jornalismonobrasilem2017.com/a-p\%C3\%B3s-verdade\%C3\%A9-uma-velha-novidade-fact-checking-n\%C3\%A3o-a19a00fba492. Acessado em: 04/05/2017.

11 Em termos simples, os algoritmos usados na programação de redes sociais são equações matemáticas que definem quais os conteúdos mais relevantes a serem apresentados a cada usuário, baseado nos modos de consumo individuais e variáveis diversas. "Cada vez mais, vamos depender de uma mistura de editores não profissionais (nossos amigos e colegas) e códigos informáticos para decidir o que ver, ler e ouvir. Esse código se baseará amplamente na força da personalização e substituirá os editores humanos profissionais [...] O futuro [...] talvez seja narrado mais por máquinas do que por pessoas" (PARISER, 2012, n.p.).

12 Em entrevista ao portal G1, Adam Mosseri, vice-presidente de produto do Facebook, afirmou: "Nós olhamos todas essas histórias e tentamos estimar ou adivinhar quais delas vão interessar a você. Tentamos prever de quais publicações você vai gostar, em quais delas você vai querer comentar, quais delas você vai querer compartilhar". Disponível em: http://g1.globo.com/tecnologia/noticia/2016/06/facebook-vai-priorizar-postde-amigo-e-familiar.html. Acessado em: 29/05/2017. 
de nossas news feed ${ }^{13}$. Considerando-se a realidade como uma construção social (BERGER; LUCKMANN, 2003), nossa compreensão de mundo variará conforme as notícias a que teremos acesso.

O grau de sucesso dessa equação algorítmica é mensurável: os usuários do Facebook gastam em média 50 minutos diários na rede, alta de $25 \%$ em relação aos 40 minutos que eram gastos em $2014^{14}$. Em um contexto local, os usuários brasileiros navegam um total de 650 horas nas redes sociais a cada mês (não apenas o Facebook), o que representa uma média mensal de 9,7 horas por visitante. O Facebook, sozinho, alcança 78\% do total de usuários únicos no Brasil (são 58 milhões de visitantes únicos mensais) ${ }^{15}$. Isso significa que aproximadamente três em cada quatro usuários de internet no Brasil acessam esta rede social.

A polarização das news feed e o contato exclusivo com fontes de consonância parece, desse modo, interessante em âmbito comercial: não só passamos cada vez mais tempo conectados às redes sociais como também essas se tornam um ambiente afetivo e passional, onde nos relacionamos apenas com pessoas, empresas e assuntos com os quais temos afinidade. Se constituem, assim, as redes de desejo tecnologicamente ampliadas, em oposição à visão tradicional a respeito das tecnologias, tidas por impessoais e ultra-racionalizadas: "Ao invés da fria desapaixonação e racionalidade do ciborgue pós-humano [...] encontramos redes que pulsam com a luxúria e a vitalidade do desejo do consumidor" (KOZINETS et al, 2017, p.679, tradução nossa).

Nessa rede de desejos, as informações que fogem ao que julgamos (ou melhor, que julgam que julgamos) como correto e agradável, ao mesmo tempo que poderiam promover a tolerância em relação ao pensamento divergente, serão evitadas, exatamente por serem fontes de desconforto cognitivo (FESTINGER, 1975).

13 "É por isso que o Facebook está se transformando numa fonte cada vez mais vital de notícias: nossos amigos e família têm mais possibilidade de saber o que é importante e relevante para nós do que qualquer editor de jornal em Manhattan" (PARISER, 2012, n.p.). Leia mais a respeito da mudança no algoritmo do Facebook na matéria do New York Times: "Facebook to Change News Feed to Focus on Friends and Family". Disponível em: https://www.nytimes.com/2016/06/30/technology/facebook-to-change-news-feed-to-focuson-friends-and-family.html?mcubz=0. Acessado em: 02/06/2017.

14 Matéria do New York Times: "Facebook Has 50 Minutes of Your Time Each Day. It Wants More". O tempo conta o acesso à suíte de aplicativos do Facebook, que, além da rede social em si, conta com o Instagram e o Messenger. O tempo gasto no Whatsapp, que é também um produto da mesma corporação, não foi mensurado no estudo. Disponível em: https://www.nytimes.com/2016/05/06/business/facebook-bends-therules-of-audience-engagement-to-its-advantage.html?mcubz=0. Acessado em: 02/06/2017.

15 Para fins de comparação, o tempo mensal total de navegação dos brasileiros em portais de notícias é de 360 horas, 290 horas a menos que o tempo dedicado às redes sociais. Disponível em: http://blog.aotopo.com.br/wp-content/uploads/2015/02/Futuro-Digital-do-Brasil-em-Foco-2015ComScore.pdf. Acessado em: 24/05/2017. 
O consumo de informações que se ajustam às nossas ideias sobre o mundo é fácil e prazeroso; o consumo de informações que nos desafiam a pensar de novas maneiras ou a questionar nossos conceitos é frustrante e difícil. É por isso que os defensores de uma determinada linha política tendem a não consumir a mídia produzida por outras linhas. Assim, um ambiente de informação baseado em indicadores de cliques favorecerá o conteúdo que corrobora nossas noções existentes sobre o mundo, em detrimento de informações que as questionam (PARISER, 2012, n.p.).

$\mathrm{O}$ acesso a informações é reduzido ao nosso meio afetivo individual; nos informamos a partir da afinidade: a pós-verdade - que, vale lembrar, refere-se a um momento em que "[...] fatos objetivos são menos influentes na formação da opinião pública do que apelos à emoção e crença pessoal” (THE WORD OF THE YEAR..., 2017, tradução nossa) - floresce num ambiente em que nossas fontes de informação são, exatamente, as nossas próprias relações afetivas.

Fumagalli (2010), ao aprofundar a noção de "capitalismo cognitivo", ressalta um outro lado do avanço do controle subjetivo por parte das empresas capitalistas, que adentram agora o âmbito pessoal: o uso das redes sociais pode ser tido por um "momento de lazer"; contudo, ao postarmos fotos e textos nestes sites, estamos produzindo conteúdo para eles - todo o conteúdo, de fato. Ou seja, trabalhando - e as informações pessoais postadas, valiosas sob diversos aspectos, serão utilizadas das mais variadas formas sem que, no mais das vezes, tenhamos qualquer controle sobre isso16.

Ademais, em um cenário de cada vez menor contato com modos de saber divergentes, os fins políticos dado às tecnologias que pulsam em consonância podem ser preocupantes, uma vez que afeitos a extremismos: Jair Bolsonaro, por exemplo, deputado federal do Partido Progressista envolvido em casos de violência e machismo ${ }^{17}$, utiliza amplamente o WhatsApp, aplicativo de conversas instantâneas, para a comunicação com apoiadores, que também agem autonomamente, espalhando notícias que politicamente interessam a ele (independente de respaldarem a realidade ou não) de maneira ampla e organizada ${ }^{18}$. O público-alvo é,

16 Recentemente, o Facebook admitiu o vazamento de dados de 87 milhões de perfis na rede. "Facebook admite uso indevido de dados de 87 milhões de usuários, 443 mil no Brasil”. Disponível em: https://noticias.uol.com.br/ultimas-noticias/bbc/2018/04/04/facebook-diz-que-cambridge-analytica-coletouindevidamente-dados-de-87-milhoes-de-usuarios.htm. Acesso em: 30/06/2018.

17 Em um caso bastante repercutido, Bolsonaro afirmou que a deputada federal pelo Partido dos Trabalhadores Maria do Rosário não merecia ser estuprada pelo fato de ser "muito feia". Bolsonaro virou réu no Supremo Tribunal Federal devido ao caso. Disponível em: http://g1.globo.com/politica/noticia/2016/06/bolsonarovira-reu-por-falar-que-maria-do-rosario-nao-merece-ser-estuprada.html. Acessado em: 08/06/2017.

18 A BBC Brasil acompanhou alguns dos administradores das páginas e grupos de apoio a Bolsonaro. São mais de 80 grupos de WhatsApp com membros de todo o Brasil, além do largo alcance no Facebook (a página 
principalmente, potenciais eleitores de Bolsonaro nas eleições de 2018, caso sua candidatura à presidência do Brasil se confirme. Assim, o discurso do deputado se alastra por meios íntimos de transmissão de informação, redes de afeto que amplificam o alcance por estabelecerem a consonância cognitiva com receptores. A longo prazo, essa caixa de ressonância dos nossos próprios pensamentos, ao nos levar a radicalismos, pode nos afastar por completo de visões de mundo diferentes, reservando ao Outro somente o espaço do ridículo ou do medo.

Como as pessoas esqueceram ou negligenciaram o aprendizado das capacidades necessárias para conviver com a diferença, não é surpreendente que elas experimentem uma crescente sensação de horror diante da ideia de se encontrar frente a frente com estrangeiros. Eles tendem a parecer cada vez mais assustadores, porque cada vez mais alheios, estranhos $\mathrm{e}$ incompreensíveis. E também há uma tendência para que desapareçam - se é que já existiram - o diálogo e a interação que poderiam assimilar a alteridade deles em nossa vida (BAUMAN, 2009, p. 46).

\section{CONSIDERAÇÕES}

A verdade una do período moderno é pulverizada em meio a uma pluralidade de compreensões de verdade, que, paradoxalmente, não se encontram nem aprendem umas com as outras; as versões guerreiam entre si pela aclamação de Verdade Suprema. Ora, e não poderiam esses embates se darem numa perspectiva dialética e incentivarem, assim, as possibilidades da polifasia cognitiva (MOSCOVICI, 1978)? Suspeitamos que não, ao menos enquanto os mecanismos da bolha algorítmica nos levarem sempre àquilo que julgam mais confortável ao nosso sistema cognitivo e ao nosso ser consumidor, nos bombardeando com informações do Mesmo e invisibilizando o Outro. E também não enquanto nossas possibilidades de informação dependerem em tamanha grandeza desta definição algorítmica de enormes conglomerados capitalistas, união das redes financeiras e multimídias que formata uma metarrede detentora de poder extraordinário (CASTELLS, 2013).

A pós-verdade não é um fenômeno novo - historicamente, a humanidade tem falhado grosseiramente na tarefa de reconhecer valor na diversidade, protegendo-se dos pensamentos dissonantes por meio da evitação e da deslegitimação dos pontos de vista desviantes (FESTINGER, 1975; JOVCHELOVITCH, 2008). Afinal, reconhecer a existência de diferentes tipos de racionalidade põe abaixo a idealização narcisista do ser racional moderno, aquele capaz de ascender à luz por meio do saber quantificável e hierárquico e que vê a

oficial de Bolsonaro tem mais de 4,3 milhões de seguidores). Disponível em: http://www.bbc.com/portuguese/salasocial-39837332. Acessado em: 08/06/2017. 
aprendizagem como um movimento linear. Aceitar que nossos processos de racionalização não são únicos e nem mesmo os mais corretos nos coloca em profundo estado de dissonância, ao contestar as bases da nossa razão: "De fato, todas as tentativas de enquadrar lógicas diferentes em categorias lógicas que são nossas mostram apenas as limitações de nossa própria lógica" (JOVCHELOVITCH, 2004, p.26).

Junto ao potencial pós-moderno de reconhecer a multiplicidade de compreensões de mundo, porém, um cuidado deve ser permanente: os discursos de ódio encontram nesse relativismo espaço para pleitear legitimidade. As redes sociais fomentam tal prática ao desprivilegiar o contato com a diversidade de pensamentos. Devemos nos questionar, portanto, se a pós-verdade, em um contexto de infinitas versões de verdade, legitimará também a misoginia, o racismo, os fascismos tantos, enfim, a mixofobia - o medo do Outro (BAUMAN, 1998) -, reconhecendo-os como mais uma entre as várias possibilidades de verdade. Seria esse o destino das redes de desejos consonantes, unindo os conceitos de Kozinets et al (2017) e Festinger (1975)?

Concordamos com Eagleton (2003): mesmo os pluralistas mais devotos relutariam em caracterizar a variedade de culturas de tortura existentes como mais um exemplo da colorida tapeçaria que é a experiência humana. A nossa sugestão, conquanto, é que há na lógica fascista, a exemplo das culturas de tortura, uma contradição essencial que a transforma inevitavelmente em argumento insustentável no contexto da pós-verdade, onde a garantia de existência para qualquer saber é precisamente a heterogeneidade de conhecimento reivindicada. O fascismo não é apenas uma forma de pensar limitada: ele é incompatível à existência da colorida tapeçaria que é a experiência humana, uma vez que sua essência é exatamente negá-la. Dito isso, admitiremos coerência na lógica fascista somente na medida em que esta admitir o valor da diversidade e a possibilidade de coexistência da diferença em indivíduos e comunidades. Ao fazê-lo, contudo, deixaria de ser o que é.

\section{REFERÊNCIAS}

ARENDT, Hannah. Verdade e Política, 1967. Disponível em: http://abdet.com.br/site/wpcontent/uploads/2014/11/Verdade-e-pol\%C3\%Adtica.pdf. Acesso em: 06/06/2017.

BAUMAN, Zygmunt. O mal-estar da pós-modernidade. Rio de Janeiro: Jorge Zahar Ed., 1998.

Confiança e medo na cidade. Rio de Janeiro: Jorge Zahar Ed., 2009. 
BERGER, Peter L.; LUCKMANN, Thomas. A construção social da realidade: tratado de sociologia do conhecimento. Petrópolis: Vozes, 2003.

CASTELLS, Manuel. Redes de indignação e esperança: movimentos sociais na era da internet. Rio de Janeiro: Zahar, 2013.

EAGLETON, Terry. A Ideia de Cultura. Lisboa: Temas e Debates - Atividades Editoriais, 2003. Disponível em: http://www.pet.eco.ufrj.br/images/PDF/terry-eagleton.pdf. Acesso em: 24/04/2017.

FESTIGER, Leon. Teoria da dissonância. Rio de Janeiro, Zahar, 1975.

FUMAGALLI, Andrea. As finanças no comando bioeconômico do trabalho vivo. Revista do Instituto Humanitas Unisinos, edição 327, p.11-13, 2010. Disponível em:

http://www.ihuonline.unisinos.br/index.php?option=com_content\&view=article\&id=3172\&se cao $=327$. Acesso em: 30/06/2018.

GIDDENS, Anthony. As consequências da modernidade. São Paulo: Editora UNESP, 1991.

JOVCHELOVITCH, S. Psicologia Social, saber, comunidade e cultura. Psicologia \& Sociedade, Florianópolis, 16 (2), p. 20-31, mai./ago. 2004. 2008.

Os contextos do saber: representações, comunidade e cultura. Petrópolis, RJ: Vozes,

KOZINETS, Robert; PATTERSON, Anthony; ASHMAN, Rachel. Networks of Desire: How Technology Increases Our Passion to Consume. In: Journal of Consumer Research, vol. 43, p. 659-682. Oxford, 2017.

MERCIER, Hugo; SPERBER, Dan. Why do humans reason? Arguments for an argumentative theory. Behavioral and brain sciences, vol. 34, p. 57-111. Cambridge, 2011.

The enigma of reason: a new theory of human understanding. Cambridge, Massachusetts: Harvard University Press, 2017.

MOSCOVICI, S. A representação social da psicanálise. Rio de Janeiro: Zahar, 1978.

PARISER, Eli. O filtro invisível: o que a internet está escondendo de você. Rio de Janeiro: Zahar, 2012. Disponível em: https://lereumvicio.files.wordpress.com/2016/06/o-filtroinvisivel-eli-pariser.pdf. Acesso em: 30/05/2017.

RAMONET, Ignacio. A explosão do jornalismo: das mídias de massa à massa de mídias. São Paulo: Publisher Brasil, 2012.

SANTOS, Boaventura de Sousa. Pela mão de Alice: o social e o político na pósmodernidade. São Paulo: Cortez, 1997. 
WORD OF THE YEAR 2016 is. Oxford Dictionaries, 2017. Disponível em: https://en.oxforddictionaries.com/word-of-the-year/word-of-the-year-2016. Acesso em: 09/05/2017.

Mestrando no Programa de Pós-Graduação em Comunicação e Informação da Universidade Federal do Rio Grande do Sul (UFRGS). Bacharel em Comunicação Social - Jornalismo (UFRGS).

Valdir José Morigi

Doutor em Sociologia pela Universidade de são Paulo (USP) e professor titular da Faculdade de Biblioteconomia e Comunicação (FABICO) e professor do Programa de Pós-Graduação em Comunicação e Informação da Universidade Federal do Rio Grande do Sul (UFRGS).

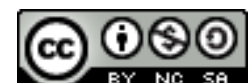

Esta obra está licenciado com uma Licença

Creative Commons Atribuição-NãoComercial-CompartilhaIgual 4.0 Internacional 